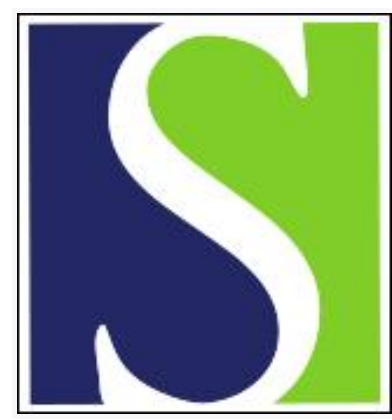

Scand J Work Environ Health 2013;39(3):310-318

https://doi.org/10.5271/sjweh.3334

Published online: 29 Nov 2012, Issue date: 01 May 2013

Illegitimate tasks associated with higher cortisol levels among male employees when subjective health is relatively low: an intra-individual analysis

by Kottwitz MU, Meier LL, Jacobshagen N, Kälin W, Elfering A, Hennig J, Semmer NK

Affiliation: University of Bern, Department of Psychology, Muesmattstrasse 45, CH - 3000 Bern 9, Switzerland. maria.kottwitz@psy.unibe.ch or norbert.semmer@psy.unibe.ch

Refers to the following texts of the Journal: 2008;34(5):337-344 2009;35(3):188-192

The following articles refer to this text: 2014;40(6):631-638;

2016;42(3):192-200; 2018;44(2):219-223

Key terms: cortisol; illegitimate task; interaction; intra-individual analysis; male employee; multilevel modeling; psychophysiology; subjective health; within-person design; work stress

This article in PubMed: www.ncbi.nlm.nih.gov/pubmed/23197336 


\title{
Illegitimate tasks associated with higher cortisol levels among male employees when subjective health is relatively low: an intra-individual analysis
}

\author{
by Maria U Kottwitz, MSc, ${ }^{1}$ Laurenz L Meier, PhD, ${ }^{1}$ Nicola Jacobshagen, PhD, ${ }^{1}$ Wolfgang Kälin, PhD, ${ }^{1}$ \\ Achim Elfering, PhD, Jürgen Hennig, PhD, ${ }^{2}$ Norbert K Semmer, PhD ${ }^{1}$
}

\begin{abstract}
Kottwitz MU, Meier LL, Jacobshagen N, Kälin W, Elfering A, Hennig J, Semmer NK. Illegitimate tasks associated with higher cortisol levels among male employees when subjective health is relatively low: an intra-individual analysis. Scand J Work Environ Health. 2013;39(3):310-318. doi:10.5271/sjweh.3334
\end{abstract}

\begin{abstract}
Objectives Illegitimate tasks refer to tasks that do not conform to what can appropriately be expected from an employee. Violating role expectations, they constitute "identity-stressors", as one's professional role tends to become part of one's identity. The current study investigated the impact of illegitimate tasks on salivary cortisol. We analyzed data on an intra-individual level, that is, by examining fluctuations in illegitimate tasks and cortisol within individuals. Furthermore, we investigated the moderating role of perceived health, expecting that illegitimate tasks evoke stronger reactions when perceived health is relatively poor.
\end{abstract}

Methods Illegitimate tasks, salivary cortisol, and perceived health were assessed in each of three waves (time lag: 6 months) in a sample of 104 male employees. Data were analyzed by multilevel analysis using group mean centering.

Results Controlling for social stressors, work interruptions, and emotional stability, the experience of more illegitimate tasks was associated with increased cortisol release if personal health resources were low compared to one's mean value of perceived health. Results cannot be explained by inter-individual differences.

Conclusions This is the first study showing that illegitimate tasks predict a biological indicator of stress, thus confirming and extending previous research on illegitimate tasks. The moderating role of perceived health confirms its importance as a personal resource, implying augmented vulnerability when perceived health is below its usual value. It is plausible to assume that increased stress reactions due to relatively poor health may further weaken available personal resources. Both avoiding illegitimate tasks and restoring personal health seem to be crucial.

Key terms interaction; multilevel modeling; psychophysiology; within-person design; work stress.

Social roles, including professional roles, often become part of people's identity $(1-3)$, and thus, the self $(1,4)$. People typically strive for maintaining a positive identity $(1,5,6)$; therefore, affirming one's role identity (eg, by being successful in a task) is an important source of pride. Conversely, threats to one's role identity are likely to induce stress $(3,7,8)$. In line with such reasoning, Thoits (9) suggested the term "identity-relevant stressors". Building on these considerations, Semmer et al (10) introduced "illegitimate tasks" as a new stressor concept. Illegitimate tasks are tasks that violate norms about what an employee can legitimately be expected to do. The (perceived) illegitimacy may derive from (i) the perception that a task does not conform to an employee's professional role, such as when experienced employees are asked to do a novice's work, or (ii) the perception that a task is unnecessary, such as having to document information that no one will ever use (11-13). Semmer et al (10) argue that illegitimate tasks do not respect the focal person's professional identity and therefore constitute an offense to the self.

Illegitimate tasks may be seen as a relatively stable ("chronic") construct, which makes sense to the degree that different jobs are characterized by different levels of illegitimate tasks in general. At the same time, however, the level of illegitimate tasks may well fluctuate

1 Department of Psychology, University of Bern, Bern, Switzerland.

2 Department of Psychology, University of Giessen, Giessen, Germany.

Correspondence to: Maria Kottwitz or Norbert K. Semmer, University of Bern, Department of Psychology, Muesmattstrasse 45, CH - 3000 Bern 9, Switzerland. [E-mail: maria.kottwitz@psy.unibe.ch / norbert.semmer@psy.unibe.ch]. 
around this general level, and thus be higher or lower at certain times.

Previous research $(11,13)$ has investigated illegitimate tasks in a chronic sense, showing that participants with higher levels of illegitimate tasks report poorer subjective well-being (eg, lower job satisfaction; more feelings of resentment towards one's organization (13) as well as more counterproductive work behavior (11); thus, these studies investigated inter-individual differences. So far, however, no studies have investigated illegitimate tasks on an occasion-specific level, analyzing changes in well-being and health within individuals over time, thus complementing the existing inter-individual analyses with intra-individual analyses. Furthermore, existing studies relied on self-report measures for assessing both stressors and outcomes, which implies the danger of inflated effects due to common method variance [(14) but see also $(15,16)]$. Finally, existing research has focused on main effects of illegitimate tasks. However, the effects of illegitimate tasks (as well as of other stressors) may not be uniform across people, and across occasions within a person. There may be differences in vulnerability between people, for instance in that people with poor health [eg, as indicated by back pain (17) or high allostatic load (18)] or certain personality characteristics [eg, low internal locus of control (19)] may be especially vulnerable. In an analogous way, intra-individual shifts in such variables over time, such as relatively poor health of an individual as compared to people's typical health status, may indicate especially vulnerable periods (20).

The present study extends existing research by (i) analyzing the association of intra-individual changes in illegitimate demands with intra-individual changes in the stress response, (ii) employing a biological indicator of the stress response, and (iii) considering the impact of illegitimate tasks in relation to differential vulnerability periods, characterized by comparatively high versus low self-reported health.

Cortisol has frequently been used as a biological stress indicator. The hypothalamic-pituitary-adrenal (HPA) axis is part of the neuro-endocrine stress response, with cortisol as its central messenger. Among healthy persons, cortisol usually displays a diurnal rhythm, with values highest in the morning and lowest in the evening. This pattern has been found to change under conditions of stress, both chronic and acute. Increased release of cortisol has been demonstrated as a response to acute stress in laboratory settings (21); however, the results of field studies have been inconclusive (22). More specifically, both increased and decreased cortisol levels have been found (23). This inconclusiveness seems to be due to several factors. First, there are large inter-individual differences in cortisol reactions (24). According to Kudielka et al (25), the majority of stud- ies investigating intra-individual effects by repeated assessments of cortisol and time-varying variables found positive associations between momentary stress and salivary cortisol. Based on this evidence, we expect higher levels of cortisol when people face high illegitimate demands, because we examined intra-individual changes (ie, changes within a person) in illegitimate tasks as predictors of intra-individual changes in cortisol over time. Second, the timing of the measurement is crucial. Lower levels of cortisol due to stress have typically been found in morning measures. By contrast, afternoon and evening measures are often higher [even in studies that found lower morning values (23)]. Therefore, we assume that cortisol levels at noon also show a tendency towards higher levels. Third, the difference between acute and ongoing versus distant stressors is important. If stressful experiences (typically traumatic experiences in this type of research) had occurred sometime before measures were taken, morning levels tended to be lower; by contrast, if stressors were still present (eg, unemployment), levels (including morning and afternoon levels) tended to be higher (23). Cortisol measures and illegitimate stressors reported at the same measurement occasion imply that illegitimate stressors are still present when cortisol is assessed. Therefore, higher, rather than lower, values of cortisol seem likely. Fourth, the nature of the stressors is important. Specifically, stressful situations that involve a social-evaluative threat tend to evoke a heightened cortisol response $(23,26)$. Illegitimate tasks are postulated to pose a threat to the self (12), which induces us to expect higher cortisol levels to be associated with higher illegitimate stressors. Each of the four factors - intra-individual differences, timing of measurement, distance to stressors, and the nature of the stressors - favors a heightened cortisol response in our study. We therefore hypothesize that intra-individual levels of illegitimate tasks will be positively related to intra-individual workday cortisol release (hypothesis 1).

The preceding considerations refer to main effects; however, it seems likely that the cortisol response is qualified by moderating variables (27). The general state of the organism in terms of health is an important factor likely to influence psychological and endocrinal responses to stress $(28,29)$. Self-reported health is a rather valid indicator of one's health status, and previous research has shown an association between self-reported health and biophysiological stress markers (30-32) although there are also studies that do not find such an association (33). On an intra-individual daily basis, Dahlgren et al (34) found poor self-reported health to be associated with higher evening cortisol levels and lower morning cortisol levels the following day. This finding is especially important for our study as it also reported intra-individual analyses and, in addition, replicated the pattern described in the meta-analysis by Miller et 
al (23) regarding lower cortisol levels in the morning but higher levels in the evening. In part, such changes may be directly due to biological processes; in addition, however, psychological processes are likely to be important. Specifically, good health can be regarded as an intra-personal resource $(20,35)$, which may mitigate responses in at least two ways. When one feels less healthy than usual, one may (i) react to stressors such as illegitimate demands with a stronger appraisal in terms of stressfulness ("...that's the last thing I need now"), and (ii) have fewer coping resources available (eg, in terms of being able to regulate one's emotions, confront one's supervisor in a constructive way, etc). As a result, the reaction to stressors is likely to be stronger compared to times when one feels fit and healthy.

Based on these considerations, we expect the association between illegitimate tasks and cortisol to be stronger on occasions when subjective health is relatively poor (hypothesis 2 ).

\section{Methods}

\section{Participants and procedure}

The data for the current analyses are from a larger longitudinal study, containing three waves, with a time lag of six months between each wave (36). Participants worked in one of three organizations: a government administration, a publicly owned production site, and a publicly owned logistics organization. We recruited participants at promotional events in the respective organization. Altogether, 509 participants were eligible for the study; we have no exact figures about how many people participated in the promotional events, but the number was considerably lower than 509 - some did not attend, some were ill, some had to do "field work". We received 176 completed questionnaires.

The present analyses refer to the male subsample of 107 employees. Data of three participants were excluded because they did not provide cortisol measures or because they were currently on medication. The resulting sample thus consisted of 104 participants, 102 of which also participated in the second and third wave. Participants worked in a variety of different jobs in administration, production (eg, metal, electronics), and logistics (transport); their age varied between 17-62 years [mean 41.21, standard deviation (SD) 11.67]. Twenty-six percent smoked (mean 5.15, SD 5.98 cigarettes). Four percent had completed primary education (9 years), 29\% had completed an apprenticeship, $54 \%$ had completed college, and $14 \%$ had a university degree. Organizational tenure ranged from 0.03-39.5 years; average tenure was 10.35 years (SD 11.16). Most of the participants $(90 \%)$ were employed fulltime; the remaining $10 \%$ ranged between $50-95 \%$ of a fulltime equivalent. Fifty-one percent had 1-4 children, with a mean of 2.28 (SD 0.77).

At each of the three waves, participants completed a general questionnaire assessing working conditions, including illegitimate tasks, and subjective health status. Cortisol and health-related behavior (like smoking) were assessed on two workdays in each wave.

\section{Measures}

Illegitimate tasks. Illegitimate tasks were measured by the Bern Illegitimate Tasks Scale [BITS (11)]. The BITS consists of eight items (eg, "Do you have work tasks to take care of, which you believe should be done by someone else?"; "Do you have work tasks to take care of, which keep you wondering if they make sense at all?"). Participants rated each item on a 5-point Likert scale, ranging from 1 (very rarely/never) to 5 (very often). Cronbach's alpha ranged from $0.85-0.86$ across the three waves.

General health. Self-reported general health was measured by a single-item measure ("How would you describe your general state of health?") on a 5-point Likert scale, ranging from 1 (poor) to 5 (very good). Across the three waves $13-19 \%$ stated $\leq 3$.

Salivary cortisol. Salivary cortisol levels were assessed at noon (before lunch) while people were at work; the assessment was linked to the routine of lunch break to increase compliance. Individuals were asked to refrain from eating, drinking (except water), brushing their teeth, and smoking one hour before measurement. In order to clarify questions and remind participants of the procedure, research assistants visited the participants at their workplace; they supervised the usage of cotton Salivette cylinders (Sarstedt, Sevelen, Switzerland), and immediately collected the samples to freeze them (below $-20^{\circ} \mathrm{C}$ ). Such a procedure is likely to be helpful in maintaining interest in the study and increasing compliance (37). Biochemical analysis of free cortisol in saliva was performed using a commercial enzyme-linked immunosorbent assay kit (DRG instruments $\mathrm{GmbH}$, Marburg, Germany). All samples were completely processed by a fully automated open system (Nexgen Four, Adaltis, Freiburg, Germany). The analytical sensitivity of the assay is $0.331 \mathrm{nmol} / 1$. All samples were analyzed in duplicates. The mean coefficient of intra-assay variance was $<5 \%$ and the one for inter-assay variance was $<10 \%$. Cortisol levels were averaged across the two days of the same wave $(r=0.51, P<0.05)$. Salivary cortisol was within an appropriate range from $0.62-16.79 \mathrm{nmol} / \mathrm{l}$. Since our data were skewed, we ran our analyses both 
with the original data and with an algorithmic transformation. These analyses yielded a very similar pattern, leading to the same conclusions; we therefore report the analyses with the original data.

Control variables. We controlled for age and nicotine use because there are indications that they are related to salivary cortisol response (24). Nicotine consumption was assessed as the number of cigarettes or cigars smoked on the respective day prior to cortisol measurement. Furthermore, we controlled for wave-specific job stressors, specifically for social stressors with colleagues and work interruptions. Social stressors refer to tensions and conflict at work, which implies a high risk of social-evaluative threat; interruptions are typically non-controllable events (38). As social-evaluative threat and uncontrollability have been found to reliably predict increases in the cortisol response (26), we controlled for these two stressors in order to be sure that illegitimate tasks are able to predict the cortisol response over and above these stressors.

Social stressors with colleagues refer to negative interactions with colleagues and were measured with a shortened version of a social stressor scale (39), containing five items (eg, "With some colleagues one often quarrels"), using a 5-point Likert scale that ranged from 1 (strongly disagree) to 5 (strongly agree). Cronbach's alpha ranged from $0.78-0.79$. Work interruptions were measured by four items (eg, "How often are you interrupted by other colleagues at work?") based on the Instrument for Stress Oriented Task Analysis (ISTA) (40). The items require a response on a 5-point scale that ranged from 1 (very seldom / never) to 5 (very often). Cronbach's alpha ranged from $0.72-0.79$.

Additionally, we controlled for the general level (ie, mean across waves) of perceived health and illegitimate tasks as well as for emotional stability at the beginning of the study [assessed by 6 items from Ostendorf's 9-item adjective list (41), which have been shown to be psychometrically adequate by Schallberger \& Venetz (42); Cronbach's alpha was 0.78].

\section{Statistical analysis}

Illegitimate tasks, perceived health, and cortisol response were measured three times per person (level 1) and, thus, are nested within persons (level 2) (43). Therefore, we analyzed our data with a random hierarchical linear modeling approach [HLM, version 6.08 (44)], using the restricted maximum-likelihood procedure. Except for nicotine, we centered all level 1 predictors at the participant's mean ("group mean centering"), which implies that the between-person variance for the particular variables is removed (45). Thus, significant coefficients for those variables reflect the effect of participants being high or low relative to their own mean for that variable across the three waves (46).

Nicotine consumption was used as a control variable on level 1 , reflecting the level of smoking at the particular measurement occasion; on level 2, we controlled for age, emotional stability plus the general level (ie, mean across waves) of perceived health and illegitimate tasks. Social stressors and work interruptions were controlled for on both levels. To confirm hypothesis 1 , there should be a significant main effect of illegitimate tasks on salivary cortisol release. To confirm hypothesis 2, the interaction term had to be significant, and the pattern of the simple slopes had to match expectations. We calculated simple slope tests using an online tool by Preacher, Curran and Bauer (47).

\section{Results}

\section{Descriptive results}

Descriptive statistics are presented in table 1. All stressors were significantly correlated on the intra-individual level. To analyze whether participants' cortisol release differed across the three waves, we calculated a null model, which yielded estimates of 0.34 for level 2 variance (between persons) and 0.66 for level 1 variance (within persons). Thus, $66 \%$ of the variance in salivary cortisol was attributable to within-person variance, indicating that examining intra-individual fluctuations by way of multilevel modeling was appropriate.

\section{Testing of hypotheses}

Results of the multilevel analyses are displayed in table 2. In model 1, we examined the effect of illegitimate tasks at level 1 (ie, wave-specific), controlling for social stressors with colleagues and interruptions at both levels, age, emotional stability and average level of illegitimate tasks at level 2, and nicotine as well as time of measurement (dummy coded) at level 1. No main effects of illegitimate tasks emerged on an intra-individual $(\mathrm{b}=0.25, \mathrm{P}>0.05)$ or on an inter-individual $(\mathrm{b}=0.21, \mathrm{P}>0.05)$ level, disconfirming hypothesis 1 .

In model 2, we additionally entered perceived health, both in terms of average across waves (level 2) and in terms of wave-specific values (level 1); no main effect emerged.

In model 3, we added the interaction term between perceived health and illegitimate tasks at level 1. In line with hypothesis 2, there was a significant interaction between illegitimate tasks and perceived health $(b=2.91$, $\mathrm{P}<0.01$ ). Model 3 showed a significant improvement over model 2 (difference of $-2 * \log =9.36, \mathrm{df}=2, \mathrm{P}<0.01$ ). 
Table 1. Means, standard deviations (SD), minimal (Min) as well as maximal (Max) values over three waves, and zero-order correlations of the study variables. Correlations below the diagonal reflect the between-person associations of the averaged level 2 variables (person; $\mathrm{N}=104$ ). Correlations above the diagonal reflect the within-person associations of the level-1 variables (measurement; $\mathrm{N} \leq 312$ ). All selfreport variables have a possible range from 1-5 with high values indicating more of the respective construct.

\begin{tabular}{|c|c|c|c|c|c|c|c|c|c|c|c|}
\hline Variable & $\mathrm{M}$ & SD & Min-Max & 1 & 2 & 3 & 4 & 5 & 6 & 7 & 8 \\
\hline 1. Cortisol a & 5.22 & 2.56 & $0.62-16.79$ & & -0.10 & -0.01 & -0.03 & $0.13^{c}$ & -0.01 & 0.04 & 0.08 \\
\hline 2. Nicotine ${ }^{b}$ & 1.34 & 4.74 & $0-50$ & -0.12 & . & -0.04 & 0.02 & $-0.12^{c}$ & -0.09 & $-0.19 c$ & -0.05 \\
\hline 3. Age & 41.21 & 11.67 & $17-62$ & -0.04 & -0.05 & . & -0.08 & -0.07 & -0.03 & $-0.15^{c}$ & 0.02 \\
\hline 4. Emotional stability & 4.37 & 0.68 & $1.00-4.33$ & 0.06 & -0.03 & 0.08 & . & $-0.26^{c}$ & $-0.28^{c}$ & $-0.30^{c}$ & $0.23^{c}$ \\
\hline 5. Work interruptions & 3.35 & 0.69 & $1.00-5.00$ & 0.15 & -0.15 & 0.15 & -0.06 & . & $0.30^{c}$ & $0.46^{c}$ & -0.06 \\
\hline 6. Social stressors & 1.56 & 0.59 & $1.00-4.40$ & -0.07 & -0.14 & -0.04 & $0.33^{c}$ & -0.06 & . & $0.51^{c}$ & $-0.16 c$ \\
\hline 7. Illegitimate tasks & 2.27 & 0.60 & $1.00-4.50$ & 0.01 & $0.29 c$ & -0.16 & $0.36^{c}$ & 0.01 & $0.57^{c}$ & . & $-0.15^{c}$ \\
\hline 8. Health & 4.15 & 0.68 & $2.00-5.00$ & 0.08 & -0.09 & 0.02 & $-0.29 c$ & -0.09 & $-0.25^{c}$ & $-0.20 c$ & . \\
\hline
\end{tabular}

a Cortisol concentration in $\mathrm{nmol} / \mathrm{l}$.

${ }^{b}$ Number of cigarettes smoked the day before cortisol measurement.

c $\mathrm{P}<0.05$ (2-tailed).

Table 2. Multilevel analyses predicting cortisol on workdays. Sample size: $\mathrm{N} \leq 312$ measures (level 1) of 104 participants (level 2). [B=unstandardized regression coefficient; $\mathrm{SE}_{\mathrm{B}}=$ standard error; $\mathrm{t}=\mathrm{t}$-value]

\begin{tabular}{|c|c|c|c|c|c|c|c|c|c|}
\hline \multirow[t]{2}{*}{ Variable } & \multicolumn{3}{|c|}{ Model 1} & \multicolumn{3}{|c|}{ Model 2} & \multicolumn{3}{|c|}{ Model 3} \\
\hline & $B$ & $\mathrm{SE}_{\mathrm{B}}$ & $\mathrm{t}$ & $B$ & $\mathrm{SE}_{\mathrm{B}}$ & $\mathrm{t}$ & $B$ & $\mathrm{SE}_{\mathrm{B}}$ & $\mathrm{t}$ \\
\hline Intercept & 4.91 & 0.25 & $19.57^{a}$ & 4.90 & 0.25 & $19.73^{a}$ & 4.81 & 0.24 & $20.19^{a}$ \\
\hline \multicolumn{10}{|l|}{ Level 2 (person) } \\
\hline Age & -0.01 & 0.01 & -0.41 & -0.01 & 0.01 & -0.41 & -0.01 & 0.01 & -0.49 \\
\hline Emotional stability & 0.08 & 0.31 & 0.28 & 0.02 & 0.30 & 0.08 & -0.02 & 0.30 & -0.05 \\
\hline Average work interruptions & 0.38 & 0.31 & 1.25 & 0.41 & 0.32 & 1.30 & 0.40 & 0.34 & 1.19 \\
\hline Average social stressors & -0.34 & 0.44 & -0.76 & -0.28 & 0.46 & -0.61 & -0.19 & 0.45 & -0.41 \\
\hline Average illegitimate tasks & 0.21 & 0.69 & 0.30 & 0.22 & 0.67 & 0.32 & 0.15 & 0.69 & 0.21 \\
\hline Average health & $\cdot$ & $\cdot$ & · & 0.32 & 0.39 & 0.82 & 0.36 & 0.39 & 0.90 \\
\hline \multicolumn{10}{|l|}{ Level 1 (wave) } \\
\hline Wave 2 & 0.66 & 0.34 & 1.94 & 0.67 & 0.34 & 1.97 a & 0.72 & 0.34 & $2.13^{a}$ \\
\hline Wave 3 & 0.43 & 0.28 & 1.54 & 0.45 & 0.28 & 1.60 & 0.55 & 0.29 & 1.91 \\
\hline Nicotine & -0.03 & 0.03 & -1.38 & -0.03 & 0.03 & -1.30 & -0.02 & 0.02 & -1.02 \\
\hline $\begin{array}{l}\text { Wave-specific work } \\
\text { interruptions }\end{array}$ & 0.79 & 0.35 & $2.24^{a}$ & 0.78 & 0.36 & $2.17^{a}$ & 0.86 & 0.37 & $2.34^{\mathrm{a}}$ \\
\hline Wave-specific social stressors & 0.57 & 0.36 & 1.60 & 0.56 & 0.36 & 1.56 & 0.42 & 0.38 & 1.11 \\
\hline Wave-specific illegitimate tasks & 0.25 & 0.41 & 0.60 & 0.27 & 0.40 & 0.67 & 0.35 & 0.41 & 0.86 \\
\hline Wave-specific health & $\cdot$ & $\cdot$ & · & 0.16 & 0.27 & 0.60 & 0.09 & 0.27 & 0.31 \\
\hline Illegitimate tasks $\times$ health & . & . & . & · & . & . & -2.91 & 1.11 & $-2.62^{a}$ \\
\hline
\end{tabular}

a $\mathrm{P}<0.05$ (2-tailed).

According to simple slope tests, illegitimate tasks were positively related to increased cortisol release when wavespecific self-reported health was relatively poor $(b=1.43$, $\mathrm{t}=2.67, \mathrm{P}<0.01)$ but not when it was medium $(\mathrm{b}=0.35$, $\mathrm{t}=0.86, \mathrm{P}=0.39)$ or high $(\mathrm{b}=-0.72, \mathrm{t}=1.16, \mathrm{P}=0.25)$. This pattern is in line with hypothesis 2 (see figure 1). In line with statistical tradition (48), we chose values $1 \mathrm{SD}$ below and above the group-centered sample mean, which approximately correspond to the $15^{\text {th }}$ and $85^{\text {th }}$ percentile. These results are independent of the average level of perceived health and illegitimate tasks, emotional stability, and the effects of work interruptions and social stressors. Social stressors showed no effect on either level. Work interruptions showed no effect on level 2, but did show a wave-specific effect (level 1), with higher levels of work interruptions resulting in higher salivary cortisol concentrations $(b=0.86, P<0.05)$. No main effects of self-reported general health emerged between $(b=0.36$, $\mathrm{P}>0.05)$ or within $(\mathrm{b}=0.09, \mathrm{P}>0.05)$ persons.

\section{Discussion}

We proposed that illegitimate tasks trigger physiological stress-responses and are thus positively related to salivary cortisol. Moreover, based on the Allostatic Load model $(28,29)$ and general resource models [eg, the Conservation of Resources (COR) model (20); the Reserve Capacity model (35)], we proposed a moderating role of self-reported health, in that the association between illegitimate tasks and cortisol should be stronger for participants in times of relatively poor, as compared to good, health. There was no main effect of 


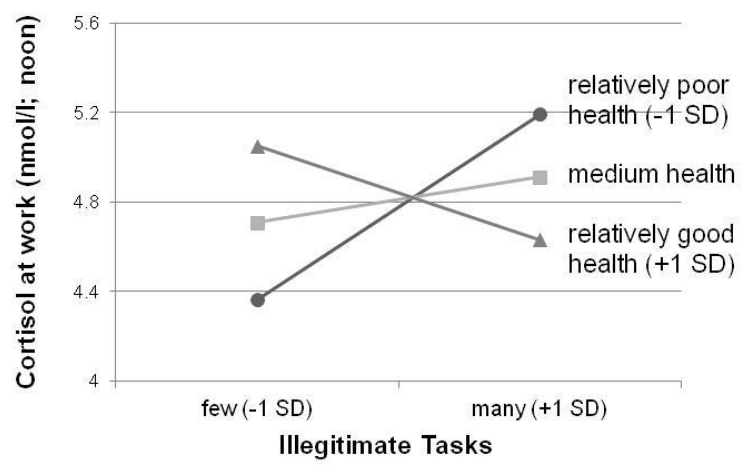

Figure 1. Interaction between illegitimate tasks and health predicting cortisol at workday. [SD=standard deviation]

illegitimate tasks; however, the proposed interaction did emerge: Illegitimate tasks predicted cortisol only in waves in which participants rated their health comparatively low. Such a finding is not uncommon in occupational stress research. When people have high resources, they may better be able to cope with stressors or be less inclined to appraise them as highly stressful in the first place (27). Under such circumstances, main effects are to be expected only when stressors are rather intense, which is not the case in our study (cf. the relatively low means for illegitimate tasks). In line with this reasoning, many studies have found the effects of stressors to be qualified by resources, both external [eg, social support (49) and internal (eg, self-esteem $(50,51)]$. The current study is the first one to show such effects for illegitimate tasks as a stressor and for perceived health as vulnerability factor.

Several features of our study are likely to have contributed to the finding of increased levels of cortisol, given that research in the field has yielded rather inconsistent results, with some studies finding elevated, but others reduced cortisol levels (23). Stress is typically associated with elevated cortisol levels in proximal or ongoing situations, such as daily experiences or, in our case, measurement occasions (23). Furthermore, higher levels of cortisol are to be expected later in the day, as compared to the morning, and when the stressors involved imply a threat to the self. Finally, intra-individual measures are associated with elevated cortisol levels more often than inter-individual ones (25). We measured cortisol at noon, related them to a stressor that constitutes a threat to the self, and analyzed our data intra-individually.

Feeling healthy may be a rather valid proxy of allostatic load; it has been associated with biophysiological stress markers $(30-32,34)$ and has been shown to predict mortality (52). If people feel less healthy, they may appraise situations as more stressful and their cop- ing abilities may be impaired. This study is the first to show such effects for illegitimate tasks, and the effect persisted when controlling for inter-individual differences in illegitimate tasks and health (level 2) and for social stressors and interruptions at both levels.

These findings have important theoretical and practical implications. The biochemical stress marker cortisol demonstrated meaningful associations with illegitimate tasks under conditions of relatively poor health when both illegitimate tasks and health were assessed by self-report; this is important in light of criticisms that self-report measures are low in validity - a criticism that may be overstated $(16,53)$. Furthermore, our results support the assumption that the individual response to a potentially stressful situation depends on a person's current state of health. Note, however, that our results refer not to a population of patients but to working people who are, in general, comparatively healthy. "Relatively poor health" therefore still implies rather good health. The mean of perceived health was 4.15 on a scale ranging from 1-5; its SD was 0.68 , implying that people with relatively poor health (figure 1) had a value of 3.47. Health can be considered an important individual resource (20); from this point of view, our results point to the importance of resources available for coping with stressful situations, and they suggest that - of these resources - health should receive more attention. For instance, interventions that improve health (through job and organization design, and/or health behavior) are likely to improve resilience to stress. It is conceivable that the physiological stress reaction impairs selfreported health and that health, at the same time, leads to an altered stress reaction. Finally, our study adds to existing knowledge through its focus on intra-individual analyses, since we did not focus on differences between individuals. Rather, our results imply that the same individuals have higher cortisol values during more stressful times (as indicated by illegitimate tasks) than during less stressful times, and only if their perceived health is relatively poor (as compared to their estimation of their health on average).

There are several limitations to our study. First, our sample size was rather small, which implies limited power and therefore an extended risk to miss a significant effect. Furthermore, the effects are not very large; converting the difference in predicted cortisol levels between participants with a high (versus low) level of illegitimate tasks into Cohen's d statistic yields a value of 0.32 . That the effects are not stronger may be due to the fact that our participants were rather healthy and that we assessed cortisol assessment only once per day, at a time where the proposed increase is likely to have started, rather than in the evening, when it is likely to be more pronounced. Further research should investigate short-term effects of illegitimate tasks on cortisol release 
using several measurements across the day and employ a longer time range (eg, several years) in order to capture cumulative effects. Also, our measure of the stress response was occasion-specific (ie, the average of two days during each wave of measurement); by contrast, the wording of the illegitimate tasks measure did not refer to the current wave of measurement but to illegitimate tasks in general, thus creating a discrepancy in the time frames, which may have weakened differences between waves in illegitimate tasks and, thus, associations with occasion-specific cortisol values. Note, however, that our respondents knew that there would be three waves, and the differences in illegitimate tasks between the waves (correlations for illegitimate tasks across the three waves ranged from $r=0.54-0.71$, and $37 \%$ of the total variance in illegitimate tasks is due to changes within participants across waves) suggest they took changes in their work situation between waves into account. Nevertheless, referring more specifically to the time preceding each measurement occasion (eg, "Did you lately have work tasks to take care of..." instead of "Do you...") might have yielded stronger differences in illegitimate tasks and potentially stronger associations with cortisol.

Third, we only investigated male employees due to the fact that cortisol is highly sex-specific and depends on the menstrual cycle and oral contraceptive usage among females $[(21,24,25)$ but see $(54)]$. Therefore, conclusions can only be drawn for men. In addition, because our response rate was not very high, we cannot eliminate the possibility of a sampling bias (55). Furthermore, we did not register the time of sampling and therefore have no data on compliance with regard to timing. Given the considerable circadian variation in cortisol, our results might reflect timing rather than work stress or subjective health. Having information on the exact time of saliva sampling would have enabled us to include it in the statistical analysis $(25,54)$, possibly leading to clearer effects. Note, however, that research assistants were present at the site, reminding participants of the saliva sampling procedure and collecting the saliva samples personally; this procedure did ensure that the sampling times were not too far off the intended time. Finally, since illegitimate tasks are a relatively new stressor concept, the amount of research conducted up to now is limited $(12,13)$, so further replications of our findings are necessary; future studies should consider additional stress-related outcomes, potential mediating mechanisms, and individual differences.

This study adds to the evidence concerning the HPA stress-response and enhances knowledge regarding illegitimate tasks. Our results indicate that the perception of illegitimate tasks increases cortisol release in times of relatively impaired health. In terms of practical implications, these findings underline the importance of preventing stressful situations in general, and of being sensitive to the potential illegitimacy of task assignments in particular, especially under conditions of relatively poor health. Considering the current health status of individuals may help to prevent loss spirals that are characterized by increased undermining of personal resources (such as health), which, in turn, may induce an augmented reactivity to stressful conditions. Thus, illegitimate tasks should be avoided, especially if health is already relatively poor.

\section{Acknowledgement}

The Swiss National Science Foundation supported part of this research with a grant [SNF 2005(100011105538)] to Norbert K Semmer. The authors are associated with the Swiss National Centre of Competence in Research (NCCR) on "Affective Sciences" (director: K Scherer). Laurenz L Meier is now at the University of South Florida, Tampa, USA.

\section{References}

1. Ashforth B. Role transitions in organizational life: An identitybased perspective. Mahwah, NJ: Erlbaum; 2001.

2. Haslam SA, Ellemers N. Social identity in industrial and organizational psychology: Concepts, controversies and contributions. In: Hodgkinson GP, Ford JK, editors. International Review of Industrial and Organizational Psychology, vol 20. Chichester: Wiley; 2005. p39-118. http:// dx.doi.org/10.1002/0470029307.ch2.

3. Siegrist J. Place, social exchange and health: Proposed sociological framework. Soc Sci Med. 2000;51(9):1283-93. http://dx.doi.org/10.1016/S0277-9536(00)00092-7.

4. Sluss DM, Ashforth BE. Relational identity and identification: Defining ourselves through work relationships. Acad Manag Rev. 2007;32(1):9-32. http://dx.doi.org/10.5465/ AMR.2007.23463672.

5. Epstein S. Cognitive-experiential self-theory. In: Barone DF, Hersen M, Van Hasselt VB, editors. Advanced personality. New York: Plenum Press; 1998. p. 211-38. http://dx.doi. org/10.1007/978-1-4419-8580-4_9.

6. Sedikides C, Strube MJ. Self-evaluation: To thine own self be good, to thine own self be sure, to thine own self be true, and to thine own self be better. In: Zanna MP, editor. Advances in experimental social psychology, vol 29. New York: Academic Press; 1997. p209-69. http://dx.doi.org/10.1016/S00652601(08)60018-0.

7. Stets JE. Examining emotions in identity theory. Soc Psychol Quart. 2005;68(1):39-56. http://dx.doi.org/10.1177/0190272 50506800104 .

8. Warr P. Work, happiness, and unhappiness. Mahwah, NJ: 
Erlbaum; 2007.

9. Thoits PA. On merging identity theory and stress research. Soc Psychol Quart. 1991;54(2):101-12. http://dx.doi. org/10.2307/2786929.

10. Semmer NK, Jacobshagen N, Meier LL, Elfering A. Occupational stress research: The "stress-as-offense-toself" perspective. In: Houdmont J, McIntyre S, editors. Occupational health psychology: European perspectives on research, education and practice, vol 2. Castelo da Maia, Portugal: ISMAI Publishing; 2007. p43-60.

11. Semmer NK, Tschan F, Meier LL, Facchin S, Jacobshagen N. Illegitimate tasks and counterproductive work behavior. Appl Psychol-Int Rev. 2010;59(1):70-96. http://dx.doi. org/10.1111/j.1464-0597.2009.00416.x.

12. Semmer NK, Jacobshagen N, Meier LL, Elfering A, Kälin W, Tschan F. Psychische Beanspruchung durch illegitime Aufgaben [Strain resulting from illegitimate tasks]. In: Junghanns G, Morschhäuser $\mathrm{M}$, editors. Immer schneller, immer mehr: Psychische Belastungen und Gestaltungsperspektiven bei Wissens- und Dienstleistungsarbeit. Wiesbaden (Germany): VS Verlag für Sozialwissenschaften / Springer Fachmedien (in press).

13. Stocker D, Jacobshagen N, Semmer NK, Annen H. Appreciation at Work in the Swiss Military Forces. Swiss J Psychol. 2010;69(2):117-24. http://dx.doi.org/10.1024/14210185/a000013.

14. Podsakoff PM, MacKenzie SB, Lee J-Y, Podsakoff NP. Common method biases in behavioral research: A critical review of the literature and recommended remedies. J Appl Psychol. 2003;88(5):879-903. http://dx.doi. org/10.1037/0021-9010.88.5.879.

15. Semmer N, Zapf D, Greif S. "Shared job strain": A new approach for assessing the validity of job stress measurements. J Occup Organ Psych. 1996;69(3):293-310. http://dx.doi. org/10.1111/j.2044-8325.1996.tb00616.x.

16. Spector PE. Method variance in organizational research. Truth or urban legend? Organ Res Met. 2006;9(2):221-32. http:// dx.doi.org/10.1177/1094428105284955.

17. Elfering A, Grebner S, Gerber H, Semmer NK. Workplace observation of work stressors, catecholamines and musculoskeletal pain in male employees. Scand J Work Environ Health. 2008;34(5):337-44. http://dx.doi.org/10.5271/ sjweh. 1280 .

18. Juster R-P, McEwen BS, Lupien SJ. Allostatic load biomarkers of chronic stress and impact on health and cognition. Neurosci Biobehav R. 2010;35(1):2-16. http://dx.doi.org/10.1016/j. neubiorev.2009.10.002.

19. Meier LL, Semmer NK, Elfering A, Jacobshagen N. The double meaning of control: Three-way interactions between internal resources, job control, and stressors at work. J Occup Health Psychol. 2008;13(3):244-58. http://dx.doi. org/10.1037/1076-8998.13.3.244.

20. Hobfoll SE. The influence of culture, community, and the nested-self in the stress process: Advancing conservation of resources theory. App Psychol-Int Rev. 2001;50(3):337-69. http://dx.doi.org/10.1111/1464-0597.00062.
21. Kudielka BM, Wüst S. Human models in acute and chronic stress research: Assessing determinants of individual hypothalamus-pituitary-adrenal axis activity and reactivity. Stress. 2010;13(1):1-14. http://dx.doi. org/10.3109/10253890902874913.

22. Hjortskov N, Garde AH, Ørbæk O, Hansen ÅM. Evaluation of salivary cortisol as a biomarker of self-reported mental stress in field studies. Stress Health. 2004;20(2):91-8. http://dx.doi. org/10.1002/smi.1000.

23. Miller GE, Chen E, Zhou ES. If it goes up, must it come down? Chronic stress and the hypothalamic-pituitary-adrenocortical axis in humans. Psychol Bull. 2007;133(1):25-45. http:// dx.doi.org/10.1037/0033-2909.133.1.25.

24. Kudielka BM, Hellhammer DH, Wüst S. Why do we respond so differently? Reviewing determinants of human salivary cortisol responses to challenge. Psychoneuroendocrin. 2009;34(1):218. http://dx.doi.org/10.1016/j.psyneuen.2008.10.004.

25. Kudielka BM, Gierens A, Hellhammer DH, Wüst S, Schlotz W. Salivary cortisol in ambulatory assessment-some dos, some don'ts, and some open questions. Psychosom Med. 2012;74(4):418-31. http://dx.doi.org/10.1097/ PSY.0b013e31825434c7.

26. Dickerson SS, Kemeny ME. Acute stressors and cortisol responses: A theoretical integration and synthesis of laboratory research. Psychol Bull. 2004;130(3):355-91. http://dx.doi. org/10.1037/0033-2909.130.3.355.

27. Semmer NK, Meier LL. Individual differences, work stress, and health. In: Cooper CL, Quick JC, Schabracq MJ, editors. International handbook of work and health psychology, 3rd ed. Oxford, UK: Wiley-Blackwell; 2009. p. 99-121. http://dx.doi. org/10.1002/9780470682357.ch6.

28. McEwen BS. Protective and damaging effects of stress mediators. N Engl J Med. 1998;338(3):171-9. http://dx.doi. org/10.1056/NEJM199801153380307.

29. McEwen BS. Stress, adaptation, and disease: Allostasis and allostatic load. Ann NY Acad Sci. 1998;840(1):33-44. http:// dx.doi.org/10.1111/j.1749-6632.1998.tb09546.x.

30. Goldman N, Glei DA, Chang M-C. The role of clinical risk factors in understanding self-rated health. Ann Epidemiol. 2004;14(1):49-57. http://dx.doi.org/10.1016/S10472797(03)00077-2.

31. Jylhä M, Volpato S, Guralnik JM. Self-rated health showed a graded association with frequently used biomarkers in a large population sample. J Clin Epidemiol. 2006;59(5):465-71. http://dx.doi.org/10.1016/j.jclinepi.2005.12.004.

32. Halford C, Anderzén I, Arnetz B. Endocrine measures of stress and self-rated health: A longitudinal study. J Psychosom Res. 2003;55(4):317-20. http://dx.doi.org/10.1016/S00223999(02)00634-7.

33. Halford C, Ekselius L, Anderzén I, Arnetz B, Svärdsudd K. Self-rated health, life-style, and psychoendocrine measures of stress in healthy adult women. Ups J Med Sci. 2010;115(4):266-74. http://dx.doi.org/10.3109/03009734.2 010.496910 .

34. Dahlgren A, Kecklund G, Theorell T, Åkerstedt T. Day-to- 
day variation in saliva cortisol-Relation with sleep, stress and self-rated health. Biol Psychol. 2009;82(2):149-55. http://dx.doi.org/10.1016/j.biopsycho.2009.07.001.

35. Gallo LC, Matthews KA. Understanding the association between socioeconomic status and physical health: Do negative emotions play a role? Psychol Bull. 2003;129(1):10 51. http://dx.doi.org/10.1037/0033-2909.129.1.10.

36. Berset M, Semmer NK, Elfering A, Amstad FT, Jacobshagen N. Work characteristics as predictors of physiological recovery on weekends. Scand J Work Environ Health. 2009;35(3):188 92. http://dx.doi.org/10.5271/sjweh.1320.

37. Bolger N, Davis A, Rafaeli E. Diary methods: Capturing life as it is lived. Annu Rev Psychol. 2003;54(1):579-616. http:// dx.doi.org/10.1146/annurev.psych.54.101601.145030.

38. Zijlstra FRH, Roe RA, Leonora AB, Krediet I. Temporal factors in mental work: Effects of interrupted activities. J Occup Organ Psych. 1999;72(2):163-85. http://dx.doi. org/10.1348/096317999166581.

39. Frese M, Zapf D. Eine Skala zur Erfassung von Sozialen Stressoren am Arbeitsplatz [A scale measuring social stressors at work]. Z Arbwiss. 1987;41(3):134-41.

40. Semmer NK, Zapf D, Dunckel H. Assessing stress at work: A framework and an instrument. In: Svane O, Johansen $\mathrm{C}$, editors. Work and health: Scientific basis of progress in the working environment. Luxembourg: Office for Official Publications of the European Communities; 1995. p105-13.

41. Ostendorf F. Sprache und Persönlichkeitsstruktur: Zur Validität des Fünf-Faktoren-Modells der Persönlichkeit [Language and personality structure: On the validity of the five-factor model of personality]. Regensburg: Roderer; 1990.

42. Schallberger U, Venetz. M. Kurzversionen des MRS Inventars von Ostendorf (1990) zur Erfassung der fünf "grossen" Persönlichkeitsfaktoren [Brief versions of Ostendorf's MRS inventory for the assessment of the Big Five personality factors]. Universität Zürich: Berichte aus der Abteilung Angewandte Psychologie; 1999;30:1-51.

43. Nezlek JB. An introduction to multilevel modeling for social and personality psychology. Soc Pers Psychol Compass. 2008;2(2);842-60. http://dx.doi.org/10.1111/j.17519004.2007.00059.x.

44. Raudenbush SW, Bryk A, Cheong YF, Congdon R, du Toit M. HLM 6: Hierarchical linear and nonlinear modeling. Lincolnwood, IL: Scientific Software International, Inc.; 2004.

45. Enders CK, Tofighi D. Centering predictor variables in cross-sectional multilevel models: A new look at an old issue. Psychol Meth. 2007;12(2):121-38. http://dx.doi. org/10.1037/1082-989X.12.2.121.
46. Hofmann DA, Gavin MB. Centering decisions in hierarchical linear models: Implications for research in organizations. J Manage. 1998;24(5):623-41. http://dx.d oi: $10.1177 / 014920639802400504$.

47. Preacher KJ, Curran PJ, Bauer DJ. Computational tools for probing interactions in multiple linear regression, multilevel modeling, and latent curve analysis. J Educ Behav Stat. 2006;31(4):437-48. http://dx.doi. org/10.3102/10769986031004437.

48. Aiken LS, West, SG. Multiple regression: Testing and interpreting interactions. Newbury Park, CA: Sage; 1991.

49. Heinrichs M, Baumgartner T, Kirschbaum C, Ehlert U. Social support and oxytocin interact to suppress cortisol and subjective responses to psychosocial stress. Biol Psych. 2003;54:1389-98. http://dx.doi.org/10.1016/S00063223(03)00465-7.

50. Seeman TE, Berkman LF, Gulanksi BI, Robbins RJ, Greenspan SL, Charpentier PA, Rowe JW. Self-esteem and neuroendocrine response to challenge: MacArthur studies of successful aging. J Psychosom Res. 1995;39:69-84. http:// dx.doi.org/10.1016/0022-3999(94)00076-H.

51. Pruessner JC, Hellhammer DH, Kirschbaum C. Low selfesteem, induced failure and the adrenocortical stress response. Pers Indiv Differ. 1999;27:477-89. http://dx.doi.org/10.1016/ S0191-8869(98)00256-6.

52. DeSalvo KB, Bloser N, Reynolds K, He J, Muntner P. Mortality prediction with a single general self-rated health question. A meta-analysis. J Gen Intern Med. 2006;21(3):267-75. http:// dx.doi.org/10.1111/j.1525-1497.2005.00291.x.

53. Semmer NK, Grebner S, Elfering A. Beyond self-report: using observational, physiological, and situation-based measures in research on occupational stress. In: Perrewé PL, Ganster DC, editors. Emotional and physiological processes and positive intervention strategies, vol 3. Amsterdam: JAI Press; 2004. p. 205-63. http://dx.doi.org/10.1016/S1479-3555(03)03006-3.

54. Hansen ÅM, Garde AH, Persson R. Sources of biological and methodological variation in salivary cortisol and their impact on measurement among healthy adults: A review. Scand J Clin Lab Inv. 2008;68(6):448-58. http://dx.doi. org/10.1080/00365510701819127.

55. Barr CD, Spitzmüller C, Stuebing KK. Too stressed out to participate? Examining the relation between stressors and survey response behavior. J Occup Health Psychol. 2008;13(3):232-43. http://dx.doi.org/10.1037/10768998.13.3.232.

Received for publication: 8 May 2012 